\title{
EFFECT OF HIP PARAMETERS ON FINE GRAIN CAST ALLOY 718
}

\author{
Patty Siereveld and John F. Radavich \\ Purdue University, W. Lafayette, IN 47907 \\ Tom Kelly \\ General Electric Co., Cincinnati, OH 45202 \\ Gail Cole \\ Howmet Turbine Corp., La Porte, IN 46350 \\ Robert Widmer \\ Industrial Materials Tech., Inc., N. Andover, MA 01845
}

\begin{abstract}
A study was undertaken to determine the effects of HIP parameters which would close porosity and economically reduce segregation. Cast 718 samples with boron levels of $30 \mathrm{ppm}$ were HIPed at $2050^{\circ} \mathrm{F} / 15 \mathrm{ksi} / 3 \mathrm{hr}, 2000^{\circ} \mathrm{F} / 30 \mathrm{ksi} / 6 \mathrm{hrs}$, and $1950^{\circ} \mathrm{F} / 45 \mathrm{ksi} / 9 \mathrm{hrs}$. The HIP temperature range of $2050^{\circ} \mathrm{F}$ to $1950^{\circ} \mathrm{F}$ was selected as the temperature range within which grain growth could be controlled. HIP pressures of 15-45 ksi were selected as those available in commercial HIP furnaces.

The results of the study showed that porosity was closed by all HIP cycles used. The degree of segregation varied inversely with HIP temperatures used, but residual chemical segregation was still present even after the highest temperature HIP cycle. The amount of Laves decreased as the HIP temperature increased.

The room temperature tensile properties are sharply reduced when the HIP temperature is below $2000^{\circ} \mathrm{F}$ due to insufficient $\mathrm{Cb}$ diffusing from interdendritic to dendritic areas.
\end{abstract}




\section{INTRODUCTION}

Components of fine grain cast 718 are being considered for various applications where LCF properties are critical. Regular castings of alloy 718 normally are large grained and in addition to porosity contain varying amounts of segregation which require longtime and high temperature homogenization practice $[1,2,3]$. The normal HIP cycle uses temperatures of $2125^{\circ} \mathrm{F}$ to $2175^{\circ} \mathrm{F}$ at $15 \mathrm{ksi}$ for $3-5$ hours. Because of the inherently large grains, grain growth has not been a serious problem but closure of casting porosity was the prime consideration.

Recent developments by the Howmet Turbine Components Corp. in casting technology have resulted in the production of fine grain castings of alloy 718 by a process called Microcast X. Due to the rapid solidification of the Microcast process, cast 718 with grains of ASTM 3-5 are obtained. However, the very rapid solidification of this process results in decreased segregation but extensive porosity. Both porosity and segregation need to be minimized by HIP cycles without sacrificing LCF life due to grain growth.

A study was undertaken to determine the effects of HIP parameters which would close porosity and economically reduce segregation. Cast $718 \mathrm{samples}$ with boron levels of $30 \mathrm{ppm}$ were HIPed at $2050^{\circ} \mathrm{F} / 15 \mathrm{ksi} / 3 \mathrm{hrs}, 2000^{\circ} \mathrm{F} / 30 \mathrm{ksi} / 6 \mathrm{hrs}$, and $1950^{\circ} \mathrm{F} / 45 \mathrm{ksi} / 9 \mathrm{hrs}$. The HIP temperature range of $2050^{\circ} \mathrm{F}$ to $1950^{\circ} \mathrm{F}$ was selected as the temperature range within which grain growth could be controlled. HIP pressures of 15-45 ksi were selected as those available in commercial HIIP furnaces.

\section{STRUCTURAL CHARACTERIZATION TECHNIQUES}

The structural responses of the as-cast and HIPed samples were evaluated by optical and scanning electron microscopy of electropolished and etched surfaces. Some chemical analyses were carried out with the dispersive X-ray analyzer attached to the SEM. Identification of phases was carried out on electrolytically extracted residues of selected samples and comparing the diffraction patterns to known standard patterns available at Micro-Met.

Additional heat treatments were carried out to determine the response of the HIPed structures to possible post HIP commercial cycles or heat treatments. Other non-conventional heat treatments were given to various samples to "TAG" the residual segregation by precipitation of $\delta$ or $\gamma^{\prime \prime}$ phases.

\section{RESULTS}

$\underline{\text { SEM }}$

The as-cast structural pattern as a composite-like structure with interdendritic segregation consisting of MC and Laves phases formed during solidification surrounded by precipitation of $\delta, \gamma^{\prime}$, and $\gamma^{\prime}$ phases during the cool down from temperature. The porosity is mostly found in the interdendritic regions in the as-cast condition and was closed by all HIP cycles and is easily revealed by the preparation techniques.

\section{Sample 1 - As-Cast}

Figure 1 show the wide variations of segregation present. At low magnification, the high $\mathrm{Cb}$ areas are very bright and consist of large islands of eutectic-like Laves phase with small white MC particles interdispersed in the Laves regions. The dendrites are the dark areas and contain very low amounts of $\mathrm{Cb}$. Larger and more discrete MC particles are found scattered in the dendritic areas. 

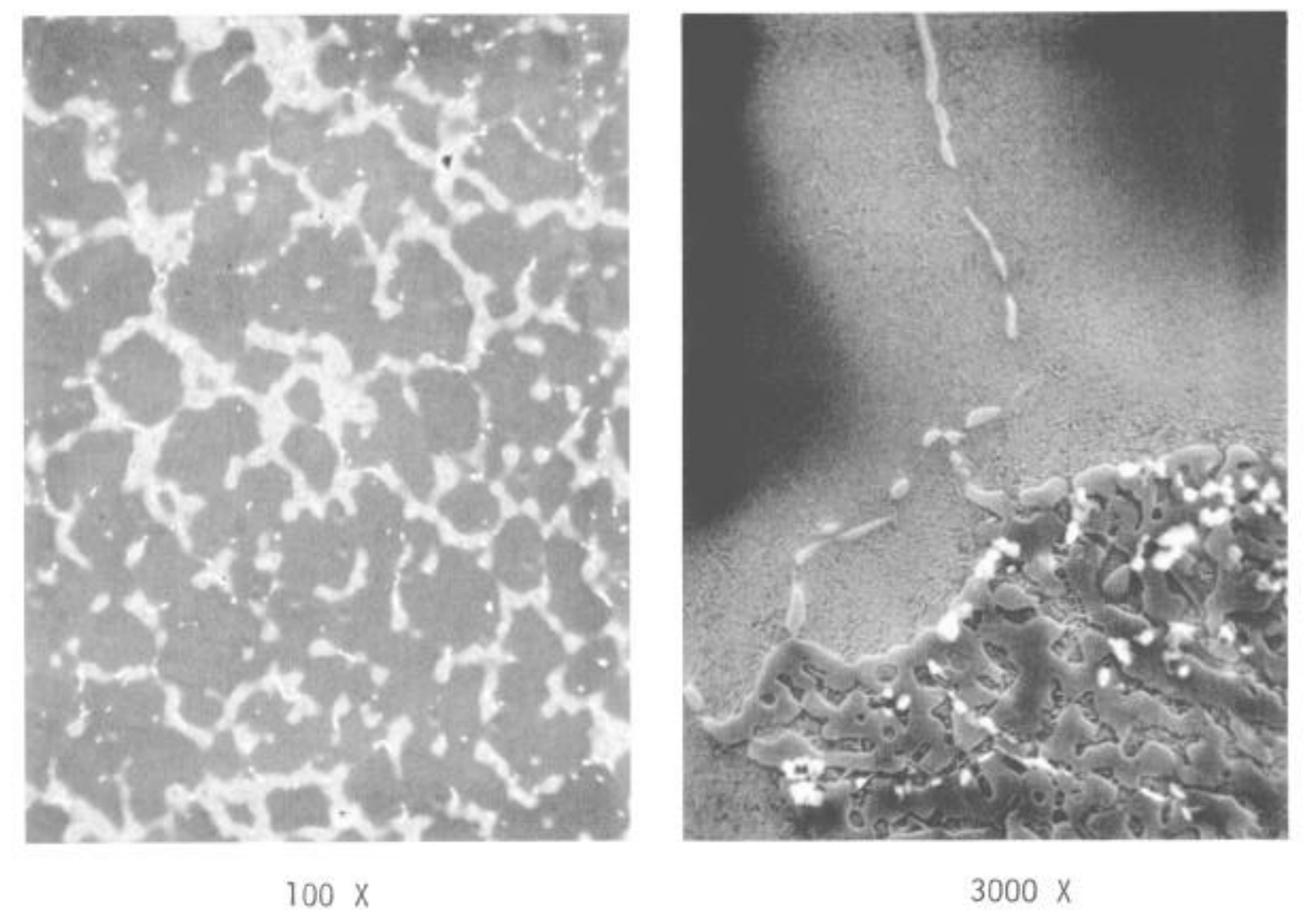

Fig. 1. As Cast

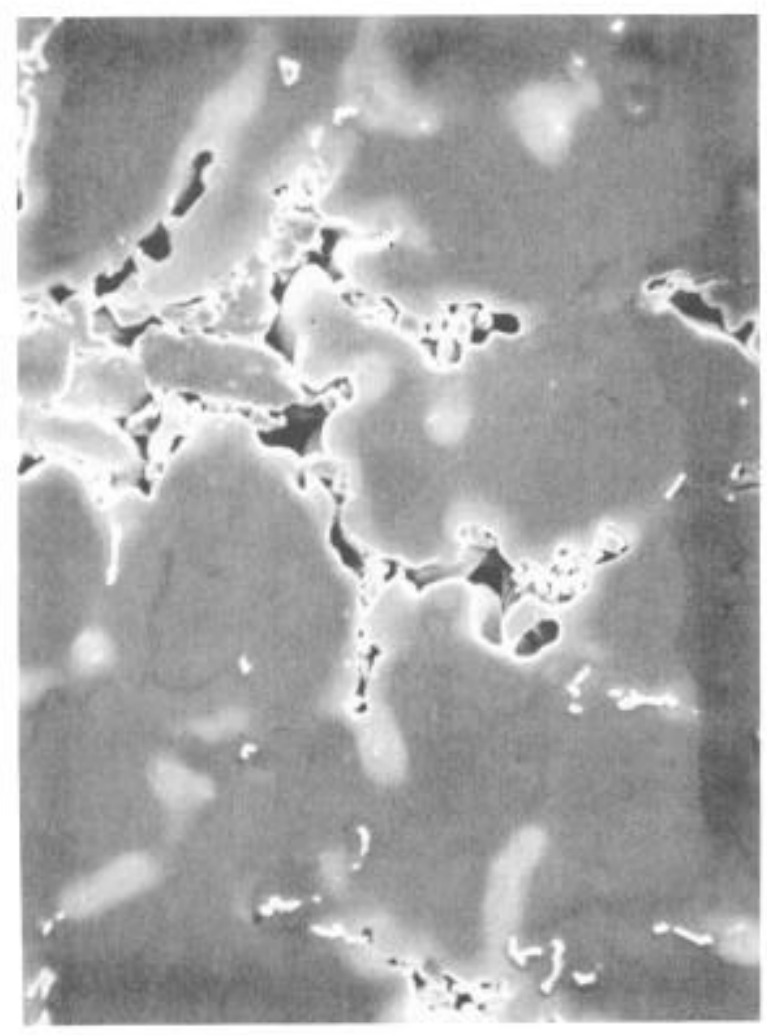

$100 x$

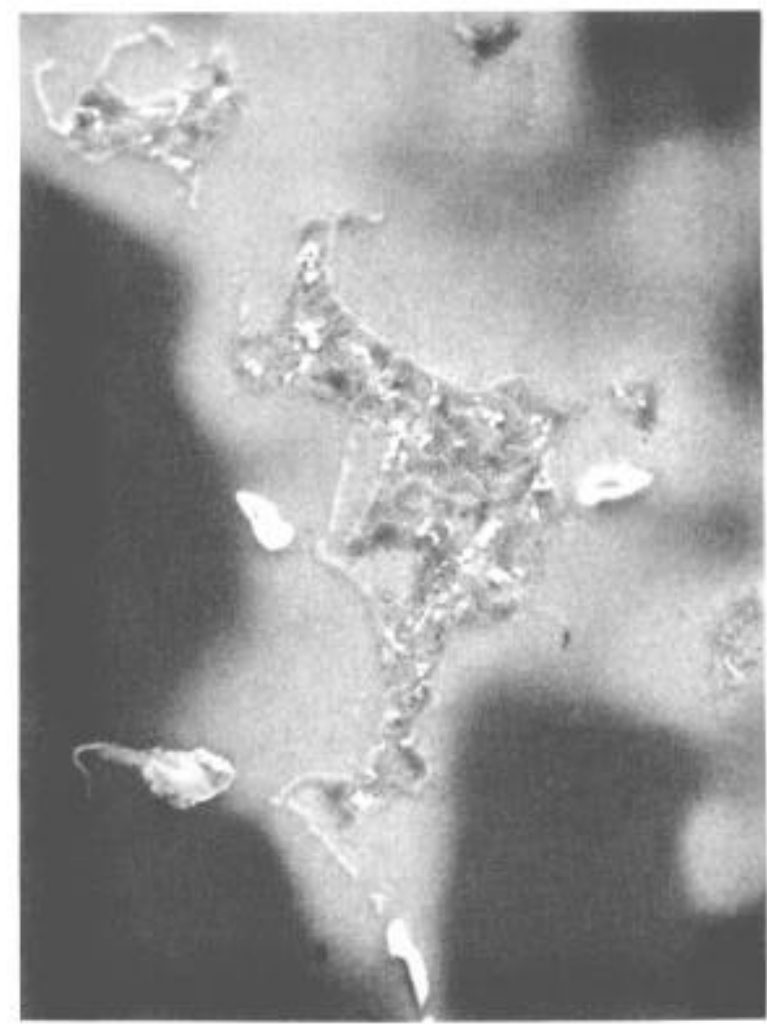

$1000 \times$ 


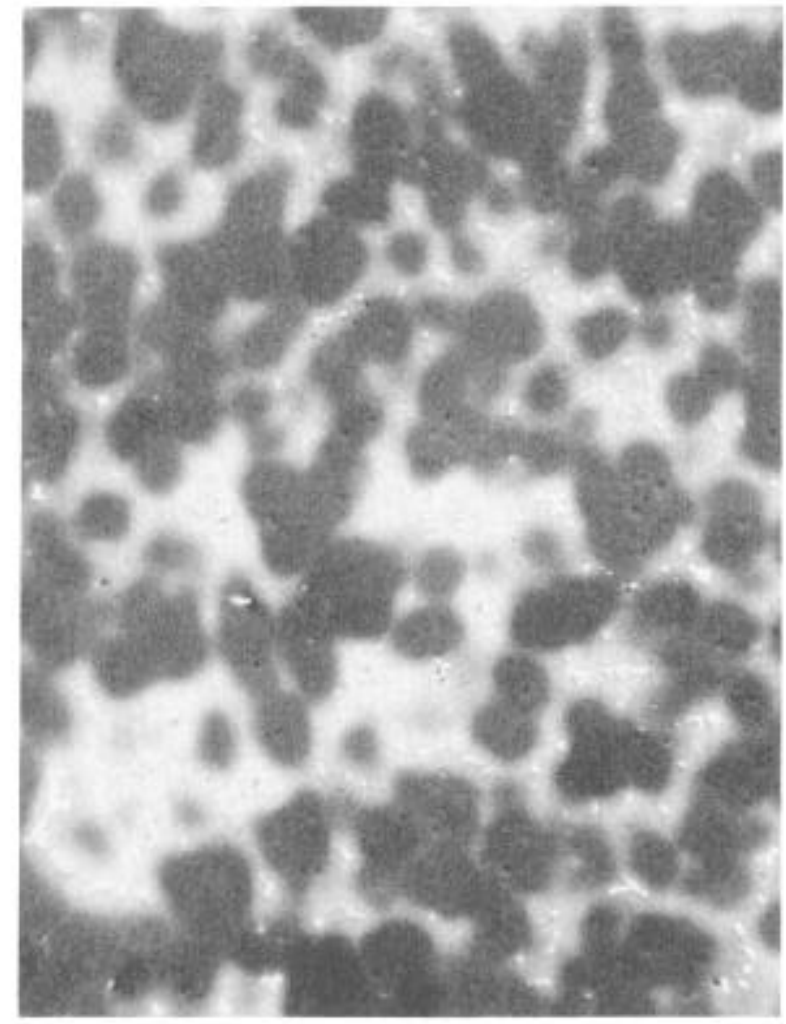

$100 \times$

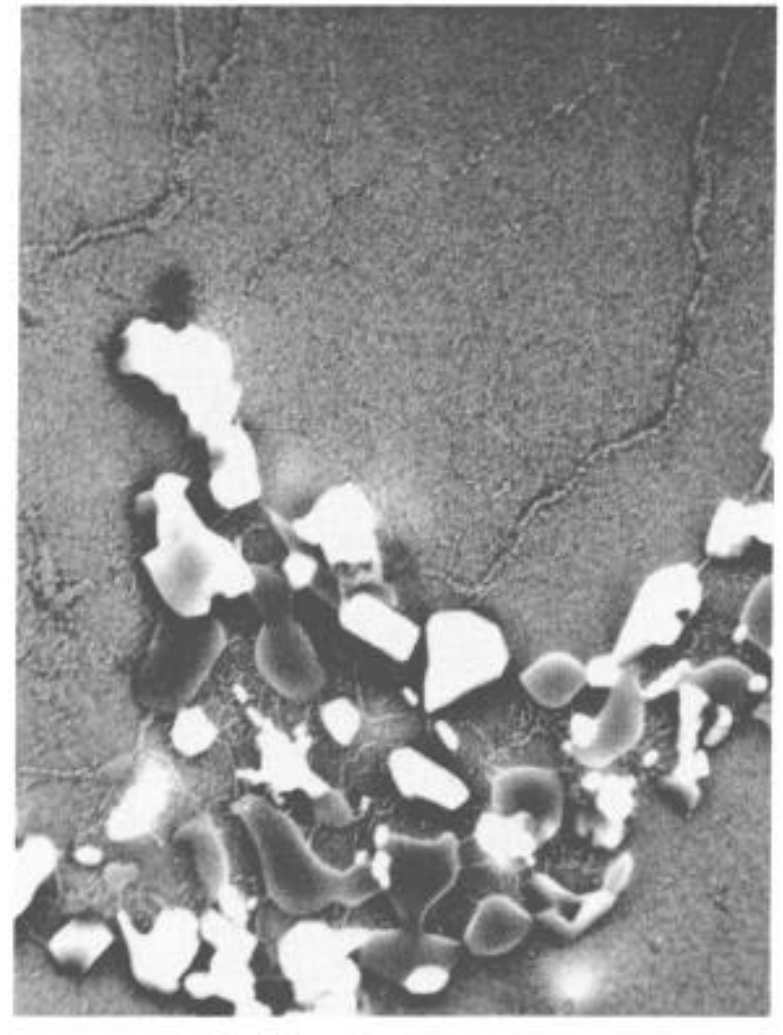

$3000 x$

Fig. 2. $2050^{\bullet} \mathrm{F} \mathrm{HIP}$

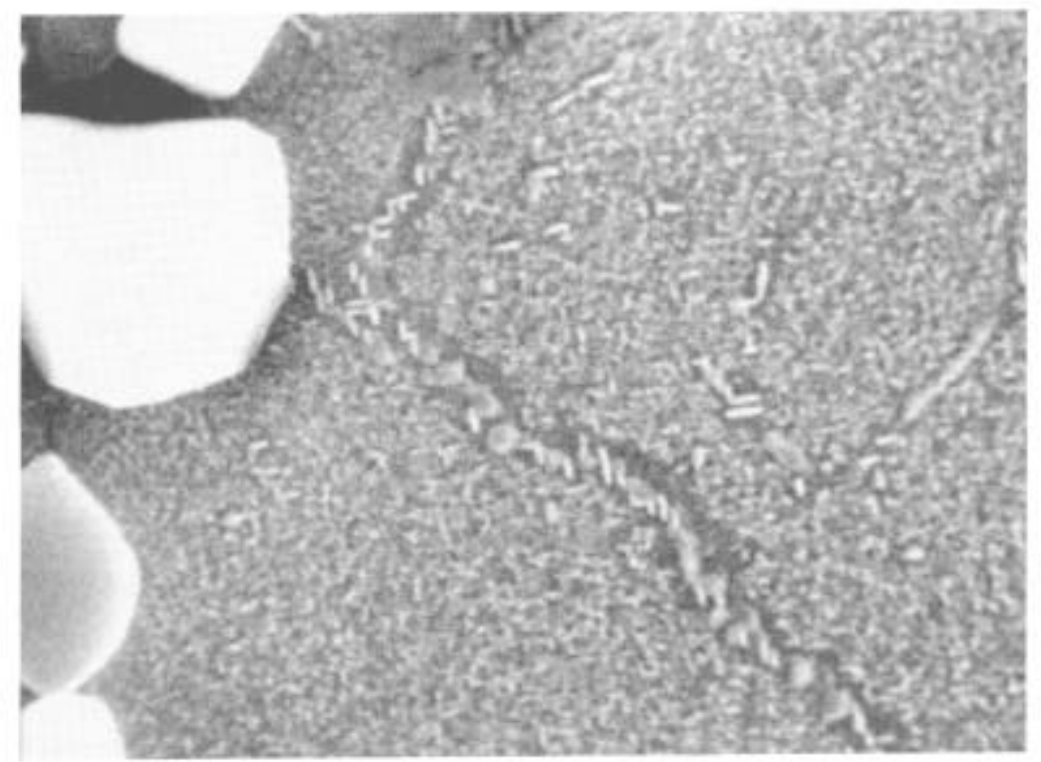

$10,000 \times$ 
The Laves island is surrounded by plates of $\gamma^{\prime \prime}$ which become smaller as the distance increases from the Laves islands into the low $\mathrm{Cb}$ dendrites. The dendrite areas show no evidence of precipitation as can be detected within the resolution of the SEM. The porosity appears to be associated with the interdendritic regions and heavy Laves precipitation.

The grain boundaries of the as-cast material show precipitation which appears to be a Laves phase. This identification is based on the similar preparation behavior of the grain boundary phase as that of the Laves islands.

Sample $13-2050^{\circ} \mathrm{F} / 15 \mathrm{ksi} / 3 \mathrm{hr}$ HIP

HIPing at $2050^{\circ} \mathrm{F}$ produces a less distinct black and white picture of segregation as compared to that of the as-cast condition, Figure 2. The white areas indicating the presence of a $\mathrm{Cb}$ rich precipitation extend further into the dendrite regions. This phase is probably $\gamma^{\prime \prime}$. No plates of large $\delta$ phase are present.

The Laves islands appear to have been broken up and an extensive large MC precipitation is formed in the Laves regions. Subgrain networks are seen extending into the dendrite areas.

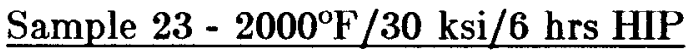

Figure 3 shows more contrast in the black and white segregation pattern than that of Sample 13. Fewer and smaller MC particles are present in the Laves areas, but more than in the original as-cast condition. The Laves islands show less tendency to have broken down. Subgrain boundaries are present and plates of $\gamma^{\prime \prime}$ appear near the Laves particles.

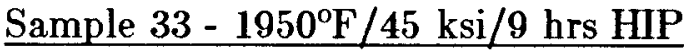

Figure 4 shows more Laves islands remaining after HIPing at this temperature, and the Laves islands are not showing any tendency to break down as seen in Figure 2. The amount of the MC formation in the Laves regions is much less than found at $2050^{\circ} \mathrm{F}$ or $2000^{\circ} \mathrm{F}$ but more than present in the as-cast condition. $\delta$ phase plates are growing from and near the Laves particles. The subgrain boundaries show small $\gamma^{\prime \prime}$ precipitation as does areas around the $\delta$ phases.

\section{Characterization of Effects of Cooling Rate}

Two samples of as-cast 718 were given a heat treatment of 3 hours at $1925^{\circ} \mathrm{F}$. One sample was furnaced cooled and the other was water quenched. Figure 5 shows the resultant phases when the sample is furnace cooled. Delta plates are growing from the Laves phase and $\gamma^{\prime \prime}$ precipitation is found in the Laves region. Porosity is very evident in the Laves areas. On the other hand when the sample is water quenched, only the MC and Laves phases are found as seen in Fig. 6. It appears that the appearance of $\delta$ and $\gamma^{\prime \prime}$ phases is a function of the cooling rate through the temperature range of $1600^{\circ} \mathrm{F}-1900^{\circ} \mathrm{F}$.

Effect of Post HIP Heat Treatment -- $1925^{\circ} \mathrm{F} / 1 \mathrm{hr}+1400^{\circ} \mathrm{F} / 5 \mathrm{hrs}$

Samples with the different IIIP cycles were given $1925^{\circ} \mathrm{F} / 1 \mathrm{hr}+1400^{\circ} \mathrm{F} / 5 \mathrm{hrs}$ thermal treatments. Figure 7 shows the changes of diffusivity of the segregation pattern due to the density of the precipitation of the $\gamma^{\prime \prime}$ phase at $1400^{\circ} \mathrm{F}$. As the 


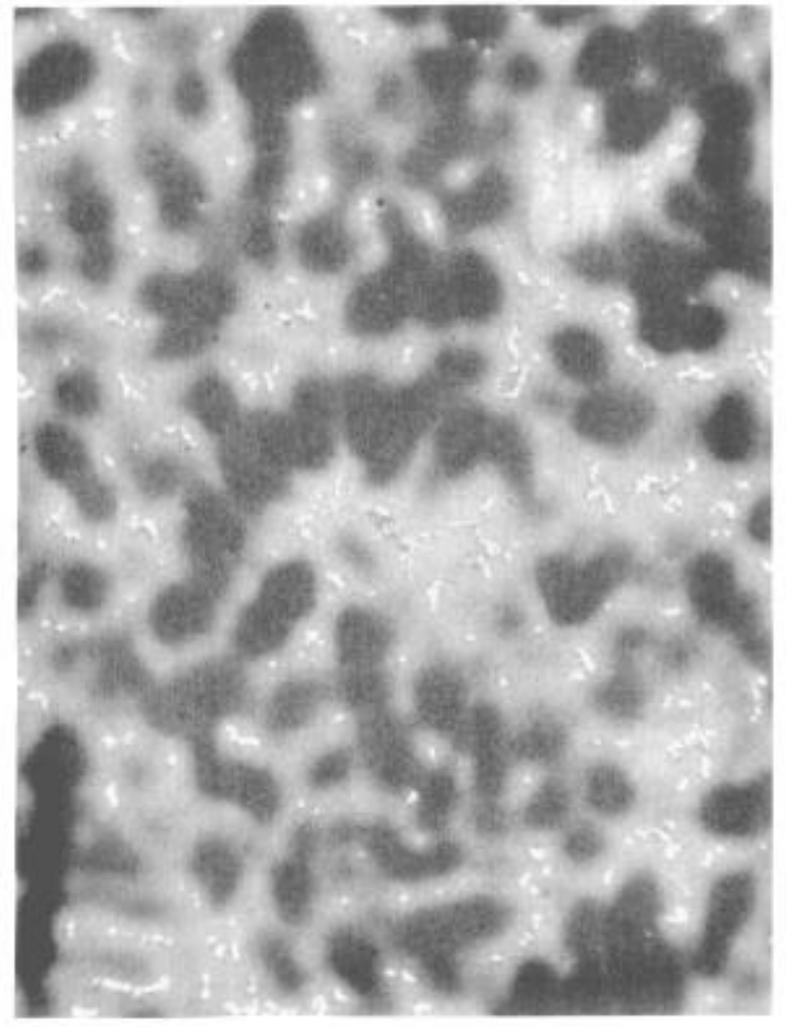

$100 \times$

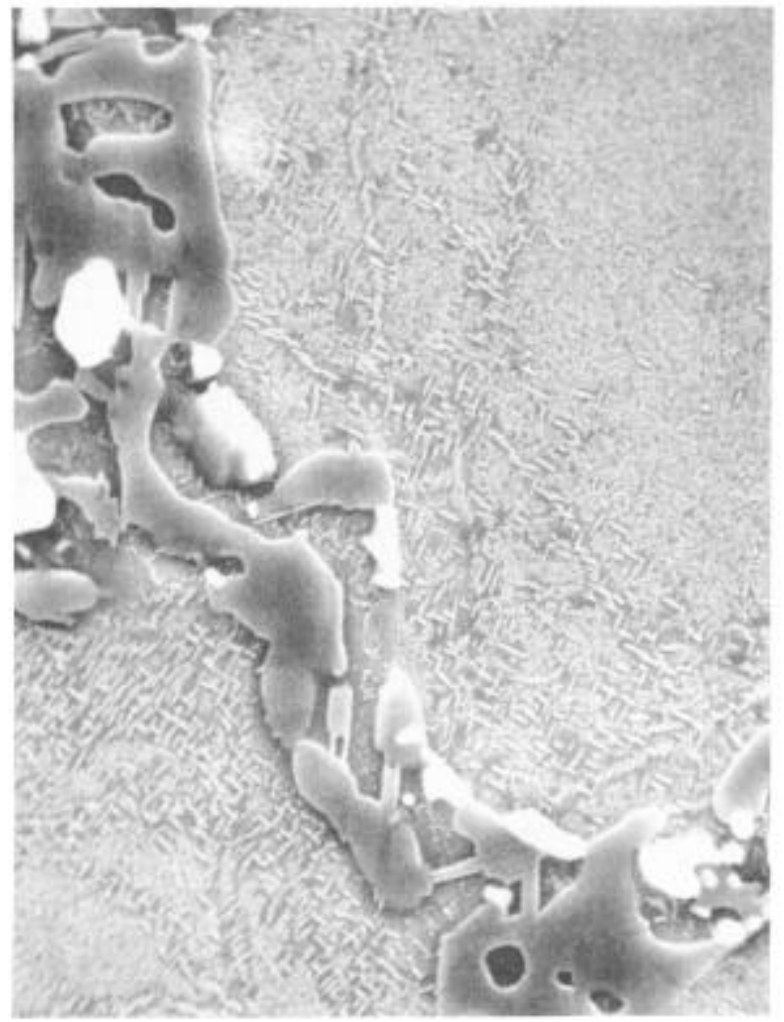

$3000 \times$

Fig. 3. $2000^{\circ} \mathrm{F} \mathrm{HIP}$

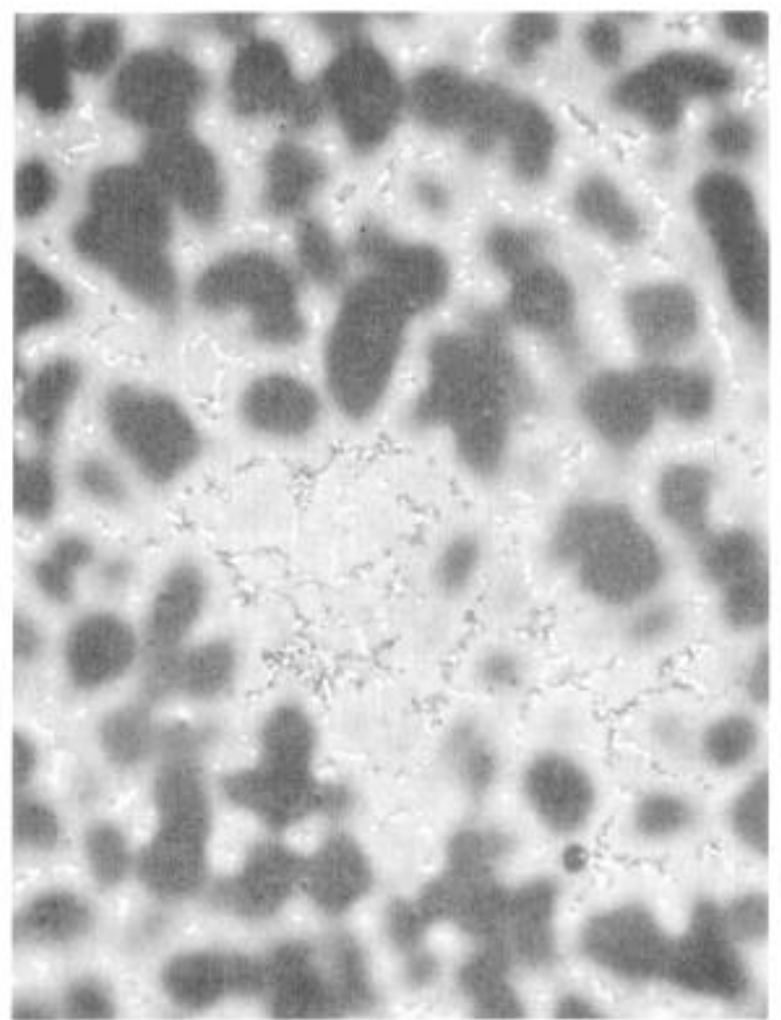

$100 \times$

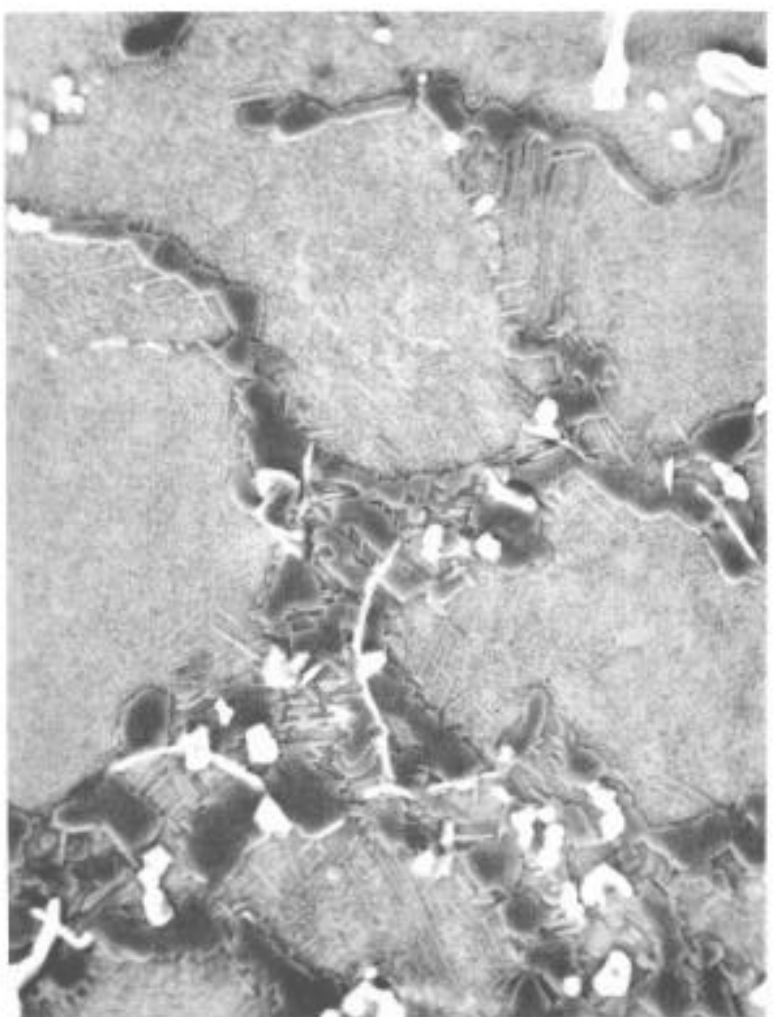

$1000 \times$

Fig. 4. $1950^{\circ} \mathrm{F}$ HIP 


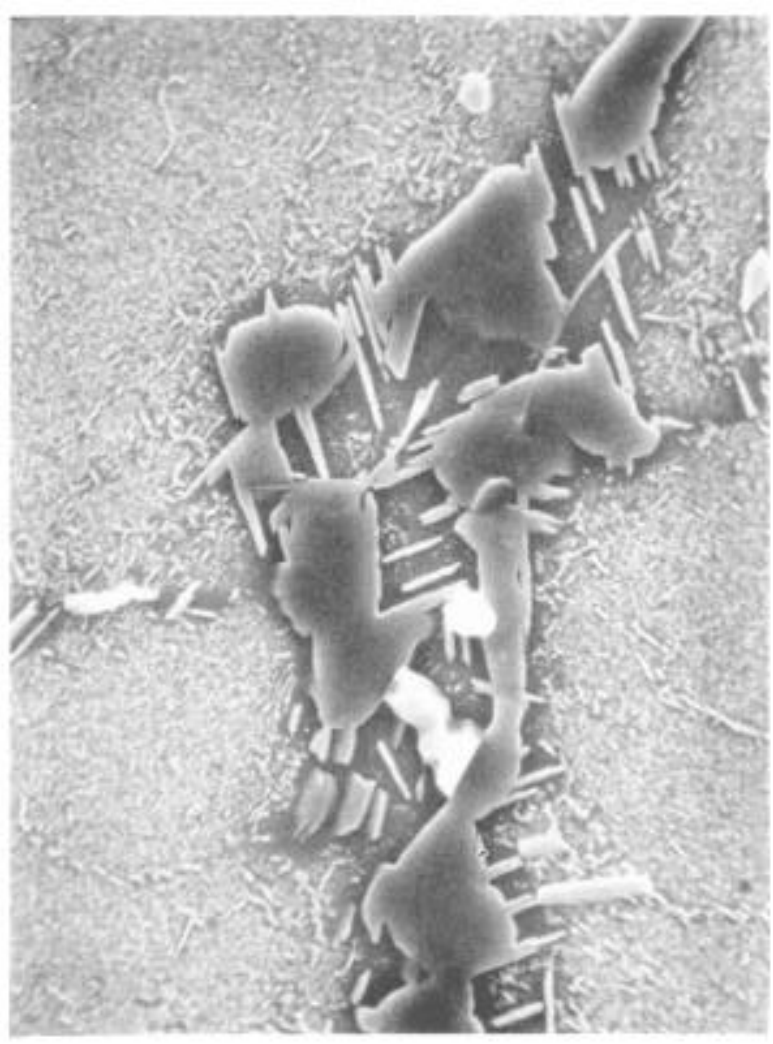

$3000 \times$

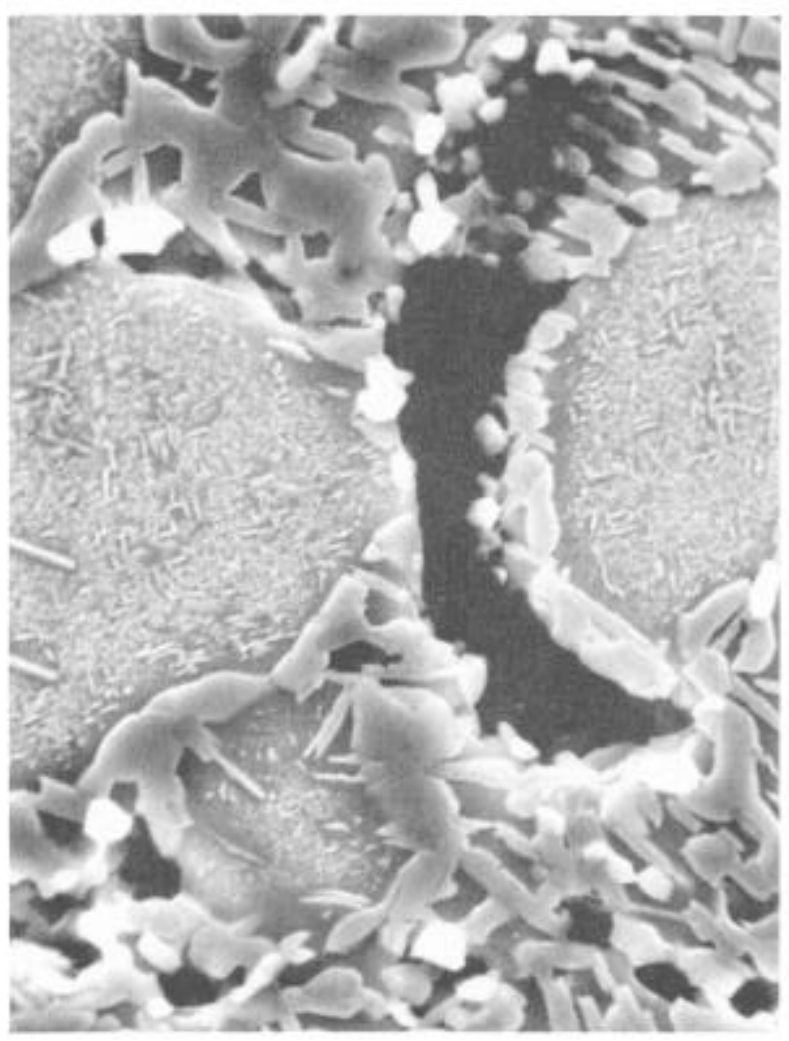

$3000 x$

Fig. 5. As Cast $+1950^{\circ} \mathrm{F} / 3 \mathrm{hr} / \mathrm{FC}$

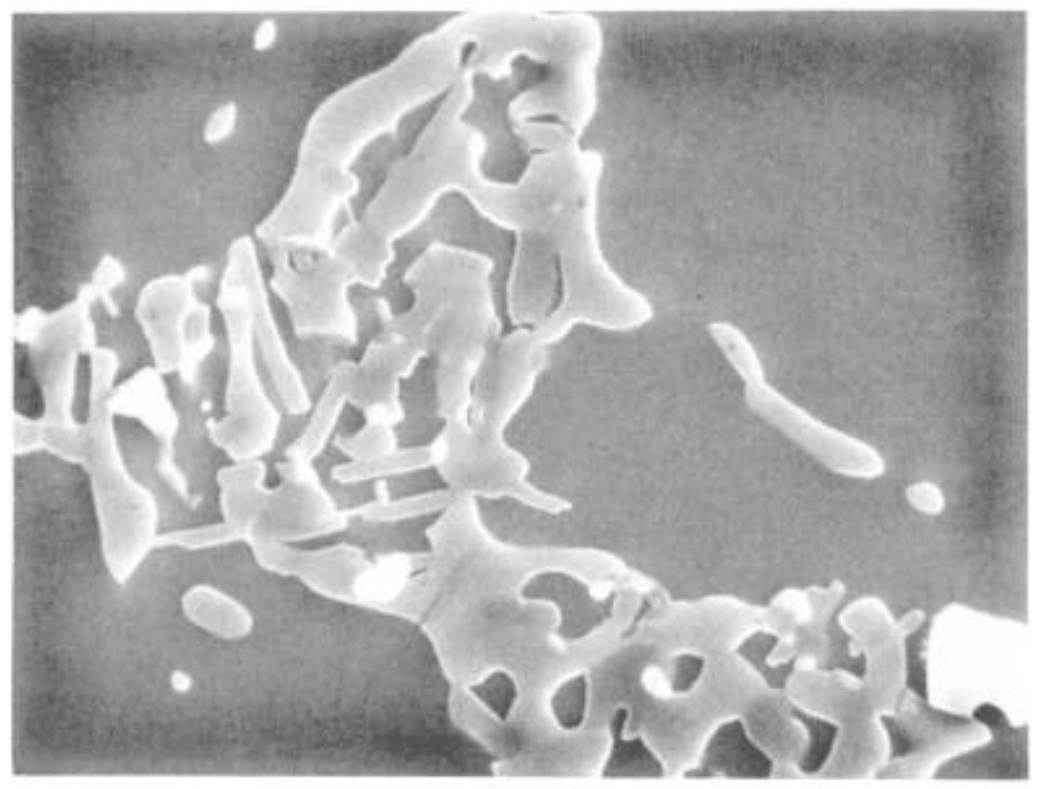

$3000 \times$

Fig. 6. As Cast $+1950^{\circ} \mathrm{F} / 3 / \mathrm{WQ}$ 


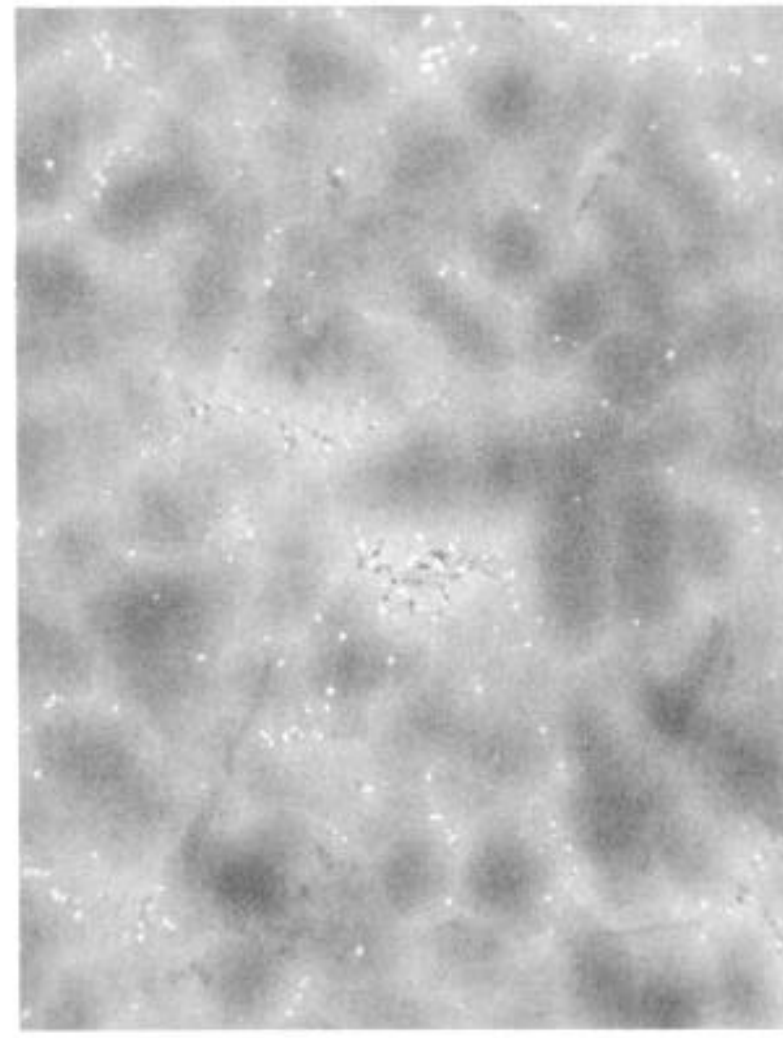

$2050^{\circ} \mathrm{F} \mathrm{HIP}$
$100 \times$

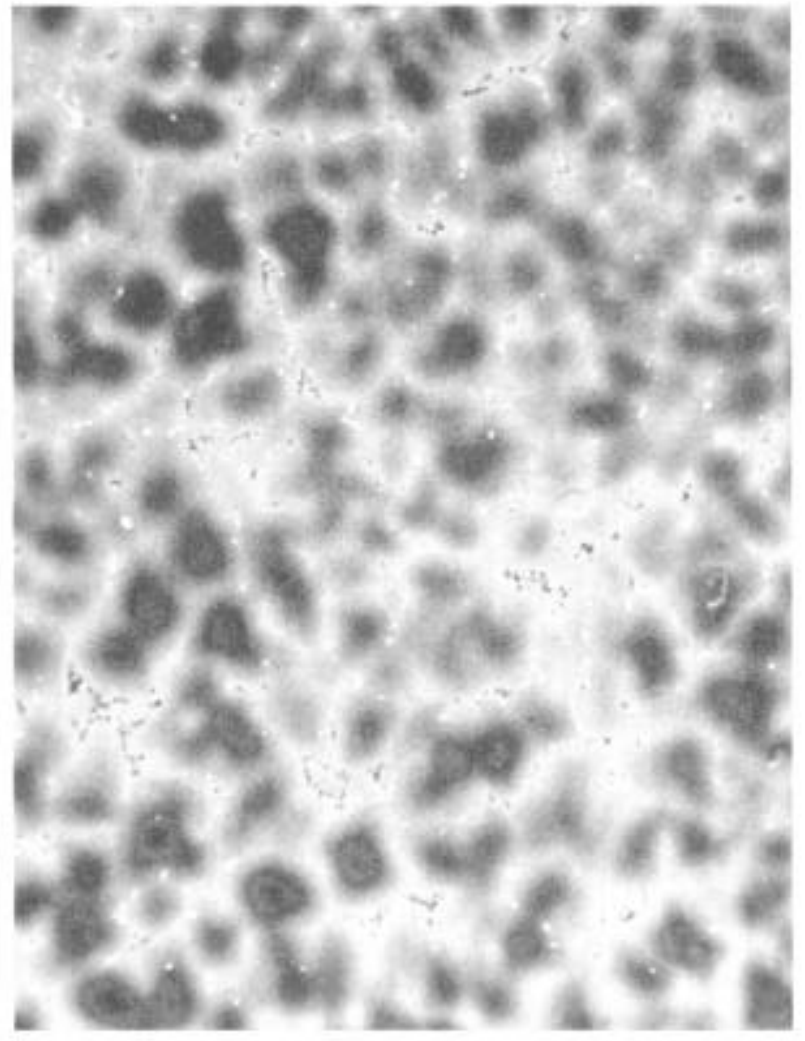

$1950^{\circ} \mathrm{F}$ HIP

$100 \times$

Fig. 7. $1950^{\circ} \mathrm{F} / 1 \mathrm{~h}+1400^{\circ} \mathrm{F} / 5 \mathrm{~h}$

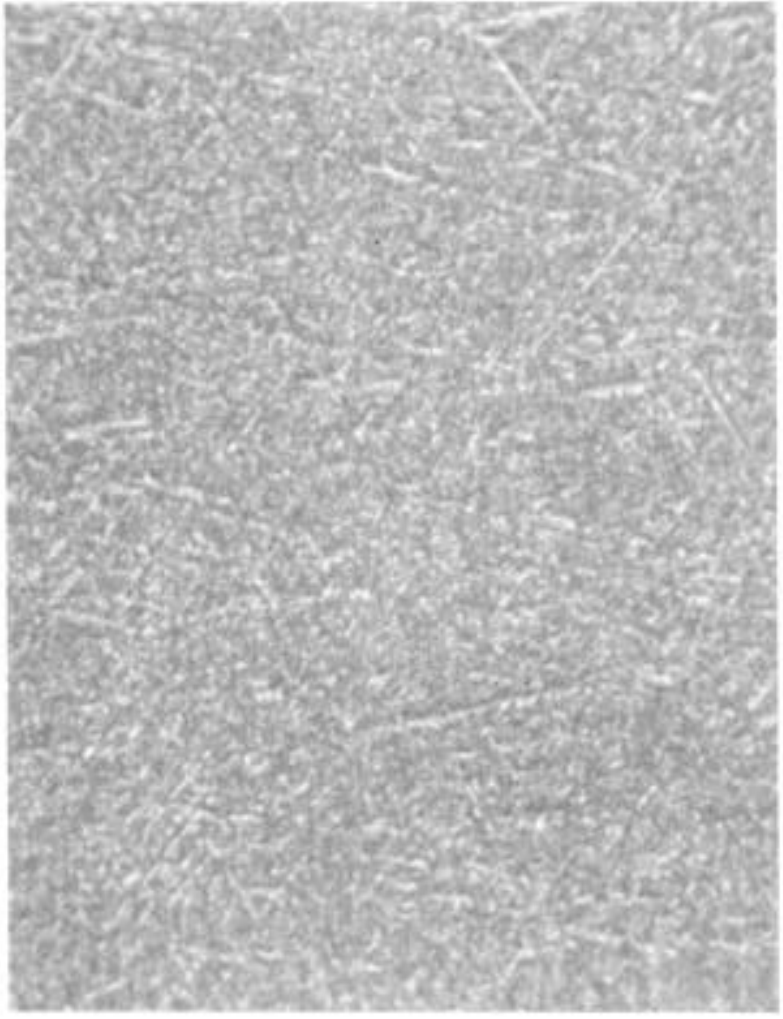

$2050^{\circ} \mathrm{F}$ HIP

$10 \mathrm{~K}$

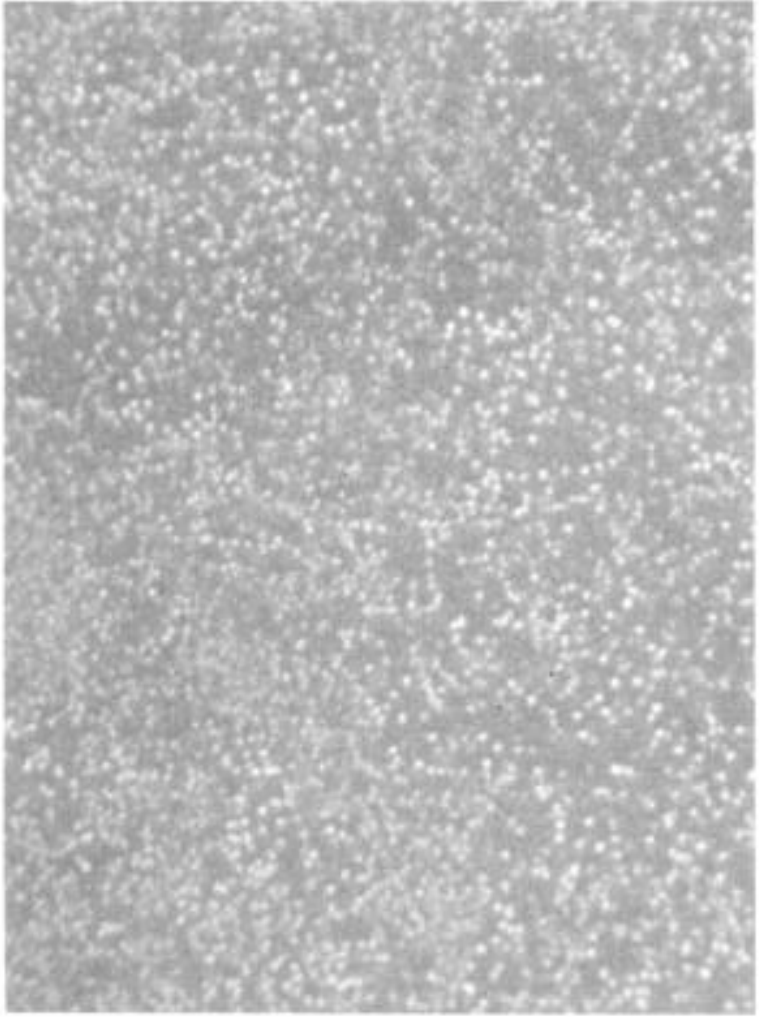

$1950^{\circ} \mathrm{F}$ HIP

$10 \mathrm{~K}$

Fig. 8. $1925^{\circ} \mathrm{F} / 1 \mathrm{~h}+1400^{\circ} \mathrm{F} / 5 \mathrm{~h}$ 
temperature of the HIP cycle is decreased, the contrast of the white and black pattern increases signifying less precipitation occurring in the dendritic areas. High magnification studies of the white areas show that the density of the precipitation in the white or high $\mathrm{Cb}$ areas decreases with decreasing HIP temperature. Figure 8 clearly shows that the dark areas precipitate fewer particles when the HIP temperatures decrease. The precipitation in the dark or dendrite regions tend to show more spheroidal shapes when the density of the precipitation is less. This precipitate may be a $\gamma^{\prime}$ phase due to the low $\mathrm{Cb}$ contents in the dendritic areas.

\section{X-Ray Diffraction Results}

The results of the X-ray diffraction studies of the extracted residues from selected samples show the as-cast phases are predominately MC and Laves phases. When the material is HIPed at increasingly higher temperatures, and longer times, the amount of the MC phase increases relative to the Laves phase.

\section{Effect of HIP Cycles on Mechanical Properties}

The effect of the HIP cycles on the room temperature tensile properties is shown in Table II. Although porosity may be closed and grain growth does not occur at temperatures as low as $1900^{\circ} \mathrm{F}$, a limitation of using a low temperature HIP cycle is that $\mathrm{Cb}$ diffusion from the interdendritic to the dendrites occurs very slowly. Dendrites which contain less than $4 \% \mathrm{Cb}$ do not precipitate the strengthening $\gamma^{\prime} / \gamma^{\prime \prime}$ phases which results in lower tensile properties as seen in Table II. Thus, to ensure adequate $\mathrm{Cb}$ diffusion, HIPing should not be carried out below $2000^{\circ} \mathrm{F}$.

TABLE II. Microcast X Mechanical Test Summary

\begin{tabular}{ccccccc}
\hline \multirow{2}{*}{$\begin{array}{c}\text { Serial } \\
\text { Number }\end{array}$} & HIP & Boron & \multicolumn{4}{c}{ Room Temp. Tensile Data* } \\
\hline 13 & $2050^{\circ} \mathrm{F} / 15 \mathrm{ksi} / 3 \mathrm{~h}$ & .003 & 169.4 & 147.4 & 12.1 & 17.8 \\
23 & $2000^{\circ} \mathrm{F} / 30 \mathrm{ksi} / 6 \mathrm{~h}$ & .003 & 168.6 & 145.6 & 12.5 & 18.7 \\
33 & $1950^{\circ} \mathrm{F} / 45 \mathrm{ksi} / 9 \mathrm{~h}$ & .003 & 156.1 & 137.2 & 6.7 & 12.0 \\
1 & $1900^{\circ} \mathrm{F} / 25 \mathrm{ksi} / 3 \mathrm{~h}$ & .003 & 146.5 & 123.6 & 5.2 & 5.5 \\
\hline
\end{tabular}

\section{CONCLUSIONS}

1. Porosity was found to be concentrated in the interdendritic regions and is associated with the Laves phase. The amount of porosity decreased with increasing boron levels. All HIP cycles closed the porosity in the cast material.

2. The degree of segregation remaining after HIPing varied inversely as the HIP temperature, i.e., less segregation with higher temperatures. The segregation pattern in the fine grain material was similar to that found in conventionally cast materials except it was on a much smaller scale due to the finer DAS. It consisted predominately of Laves and MC phases formed during the high temperature portion of the solidification surrounded by $\delta, \gamma^{\prime}$ and $\gamma^{\prime}$ phases formed 